\title{
EFFECTS OF DRIP IRRIGATION ON SPRING SOYBEAN (GLYCINE MAX (L.) MERR.) GROWTH AND SOIL PHYSICAL INDEXES OF HEILONGJIANG PROVINCE OF CHINA
}

\author{
Baoguo Zhu, Chunfeng Zhang*, Huibin Jia, Qingying Meng, Nannan Wang, \\ Enjun Kuang ${ }^{1}$, Libo Zhang, Xiaohui Shen and Xuedong Gao \\ Jiamusi Branch, Heilongjiang Academy of Agricultural Sciences, \\ Jiamusi Heilongjiang 154007, China
}

Keywords: Drip irrigation, Spring soybean, Irrigation amount, Growth, Physical index, Yield

\begin{abstract}
Effects of different drip irrigation on the growth, development and yield of spring soybean was carried out by measuring the growth index and soil physical characteristics index of spring soybean (Glycine max (L.) Merr.). On the basis of natural precipitation in the same year, 4 drip irrigation levels, namely W1 $(0 \mathrm{~mm})$, W2 $(200 \mathrm{~mm}), \mathrm{W} 3(400 \mathrm{~mm})$ and W4 $(600 \mathrm{~mm})$ were established. From flowering to the pod stage of soybean, a significant increase in the soil moisture and a reduction in the soil hardness and bulk density were observed. Though the difference between W3 and W4 was not significant, drip irrigation affected soil physical properties followed W4 $>$ W3 $>$ W2 $>$ W1. Improved growth index including plant height, above-ground biomass and leaf area of soybean was also observed, but excessive drip irrigation triggered the decline of leaf area index and above-ground biomass. Changes caused in the soil physical properties due to drip irrigation affected soybean growth, which resulted a positive action on yield. Compared with W1 treatments, soybean yield in the different irrigation in the W3, W4 and W2 in the year 2015 and 2016 were increased by 83.68 and $46.99 \%$, 61.58 and $39.47 \%, 23.51$ and $20.21 \%$, respectively. Based on the results of the present experiment it was observed that W3 treatment (irrigation rate $400 \mathrm{~mm}$ ) was the best one for the improved crop yield of soybean.
\end{abstract}

\section{Introduction}

Heilongjiang province of the People's Republic of China is a major province of agricultural interest and plays a significant role in the national food security (Zhang et al. 2014). The spatial and temporal distribution of the surface water resources of Heilongjiang is uneven. In this area, the rainfall is available mainly from July to September which accounts $60-80 \%$ of the annual total and excessive or low rainfall affects crop yield in some special years ( $\mathrm{Li}$ and Zhang 2010). So, irrigation is inevitable for the growth and development of crops. In the recent past, a number of researches were carried out to find whether the irrigation can significantly improve the dry matter accumulation, enhance photosynthesis and increase water-using efficiency of crops (Ren et al. 2015, Wang et al. 2015, Xing et al. 2015, Zhang et al. 2015, Qiang et al. 2016).

Heilongjiang is the China's main soybean producing region, accounting for about $30 \%$ of the national production, and China's soybean commodity grain base, ensuring the safety of Chinese soybean food is an important task, which is of great significance to National Soybean Industry Safety. No-tillage cultivation of soybean is a new system compared to the traditional one and it is widely used in the recent years. Studies suggest that no-tillage plays very important role in reducing soil compaction, increasing the capacity of soil moisture storage, reducing soil erosion and promoting the sustainable development of agriculture (Hamza and Anderson 2005, Zai and Tang 2008, Liu et al. 2010, Nippert et al. 2012). Under the condition of dense planting, the quality of population growth must be higher than that of water. It is very important to study the effects of different irrigation amount on the growth and development of spring soybean and the physical properties of soil. There are a few reports on these subjects (Wu et al. 2011, Zhao et al. 2014, Zhang et al. 2016). Therefore, on the basis of narrow-row and dense planting, in the present study the characteristics of rainfall in homogeneity in Heilongjiang Province, and the irrigation of

\footnotetext{
*Author for correspondence:<chunfeng-1@163.com>. ${ }^{1}$ Institute of Soil Fertilizer and Environment Resource,
} Heilongjiang Academy of Agricultural Sciences, Harbin Heilongjiang 150086, China. 
soybean was carried out during the critical period of breeding. Besides the effects of soybean yield, growth index and soil physical index, the variation and regularity of soil moisture, hardness and capacity under different irrigating capacity of dense-planting soybean were explored. The aim of this paper is to provide the theory for the construction of high yield and highly efficient water control technology of spring soybean in the Heilongjiang province of China.

\section{Materials and Methods}

The present research was carried out in the Key Laboratory of Crop Breeding and Cultivation, Jiamusi Branch of Heilongjiang Academy of Agricultural Sciences, Sanjiang plain, Heilongjiang Province $\left(45^{\circ} 56^{\prime}-48^{\circ} 28^{\prime} \mathrm{N}, 129^{\circ} 29^{\prime}-135^{\circ} 5^{\prime} \mathrm{E}\right)$, China. The climate of Heilongjiang is temperate continental monsoon, which experiences long winter but short summer. The frost-free period lasts about 130 days and its effective accumulated temperature is $2521^{\circ} \mathrm{C}$ and average rainfall is about $510 \mathrm{~mm}$. Heavy wind occurs in spring but high temperature in summer accompanied by drought in both spring and summer is prevalent.

In this experiment, soybean yield was measured in 2015-2016 for two consecutive years, and the whole region was harvested. A small self-made stabilivolt drip irrigation machine (Patent number: 201520576100.9, 2015) able to control the amount of irrigation in a definite block of crop

filed was used. Each block measured $3.8 \times 10.0 \mathrm{~m}$ and there was a total of 12 blocks over an area of $456 \mathrm{~m}^{2}$. A water tank (1000 l cap.) was connected to the experimental fields via white PVC pipes ( $3.3 \mathrm{~cm}$ dia.) containing own water valve switch. The white pipe is connected to a black pipe of test block having fine drip irrigation pipes fitted at every $34 \mathrm{~cm}$ intervals.

The experiment was conducted in meadow and 4 kinds of irrigation treatments were set. The irrigation quota was: 0, 200, 400, $600 \mathrm{~mm}$, hitherto defined as W1, W2, W3, W4, respectively. The disposal was repeated 3 times using 1 drip irrigation tube of 2 times (spacing $38 \mathrm{~cm}$ ) with the same emitter discharge and irrigation. Irrigation was provided at seedling stage every time, flowering and podding irrigations was done 2 times each, grain filling stage irrigation 2 times and whole growth period irrigation 7 times.

For the present experiment, the soybean (Glycine max (L.) Merr.) cultivar Henong 60 was used. The crop was planted following $19 \mathrm{~cm}$ narrow row and no tillage drill with a seedling

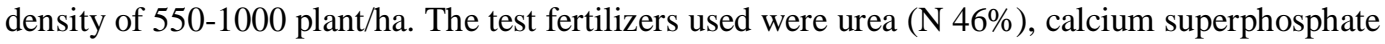
$\left(43 \% \mathrm{P}_{2} \mathrm{O}_{5}\right)$ and potassium sulfate $\left(50 \% \mathrm{~K}_{2} \mathrm{O}\right)$. The application rate of fertilizers was urea 109 $\mathrm{kg} / \mathrm{hm}^{2}$, calcium superphosphate $349 \mathrm{~kg} / \mathrm{hm}^{2}$ and potassium chloride $60 \mathrm{~kg} / \mathrm{hm}^{2}$. All these three were applied as a single basal fertilizer to the experimental field and when the crop started sprouting, the plants were sealed to separate from the weeding line. The method of sealing and weeding were consistent.

The soil water content, hardness, capacity and the height, biomass, leaf area and yield of spring soybean were measured during the experiment. The water content of the soil was measured via drilling and drying the soil as described in CSS (2000). Soil samples were collected from a vertical profile of depths ranging from $0-10,10-20,20-30,30-40,40-50,50-60 \mathrm{~cm}$. The mean value from these ranges was reported as a value for $0-60 \mathrm{~cm}$ soil depth. Soil hardness was measured by a DIK- 5521 (Japan) along a stratified sampling depth of $0,5,10,15,20,25,30,35$, $40,45,50,55$ and $60 \mathrm{~cm}$. Sampling average method was used to calculate the soil hardness and soil bulk density from $0-60 \mathrm{~cm}$ soil depth. For the later parameter drying method was used along the stratified sampling depth varying from $0-20,20-40,40-60 \mathrm{~cm}$. The soil water content, soil hardness and the soil bulk density were measured after $24 \mathrm{hrs}$ of irrigation.

Plant height $(n=25)$, above ground biomass $(n=5)$ and leaf area $(n=5)$ measurements were considered as the growth index of soybean crop. These parameters were measured at seedling, 
flowering, podding, grain filling and mature stages of the uniformly growing selected crop plants. The above ground biomass was measured by drying method and an automatic leaf area meter AAC-400 (Japan) was used to calculate the leaf area. Number of pod and seed per pod were counted $(n=5)$. Yield $(n=3)$ and yield components $(n=10)$ of soybean plant were determined. Mean value for each variable was presented.

The yield of the crops for the whole experimental blocks was estimated by selecting 30 mature representative crop plants. A similar selection of 10 plants was used each time to measure the yield components of the experimental soybean crops. All the data were analyzed by using DPS 7.05 and Excel 2003.

\section{Results and Discussion}

Soil water content at flowering, podding and filling stages of soybean in the experimental field over a soil depth profile $0-60 \mathrm{~cm}$ is presented in Fig. 1. Compared with the control (W1), an increasing trend in the soil water content was observed from W2 - W4. The increased percentages at flowering stage were $1.42-4.11,5.14-9.16$ and $4.48-9.63 \%$ in W2, W3 and W4 treatments, respectively (Fig. 1a). In pod stage, these increments followed $0.14-2.75,0.09-12.19$ and $2.65-$ $12.20 \%$ in W2, W3 and W4, respectively (Fig. 1b). At filling stage of soybean crop the trend of variation at $\mathrm{W} 2, \mathrm{~W} 3$ and $\mathrm{W} 4$ was $0.21-7.24,1.88-11.15$ and $0.29-11.54 \%$, respectively (Fig. $1 \mathrm{c})$. With the increase of irrigation amount, the soil water content increased when the irrigation amount reached $\mathrm{W} 3$ and $\mathrm{W} 4$, the water change was basically the same. The variation of soil water content in different growth stages of soybean followed a higher to lower pattern W4 > W3 > W2 > W1.
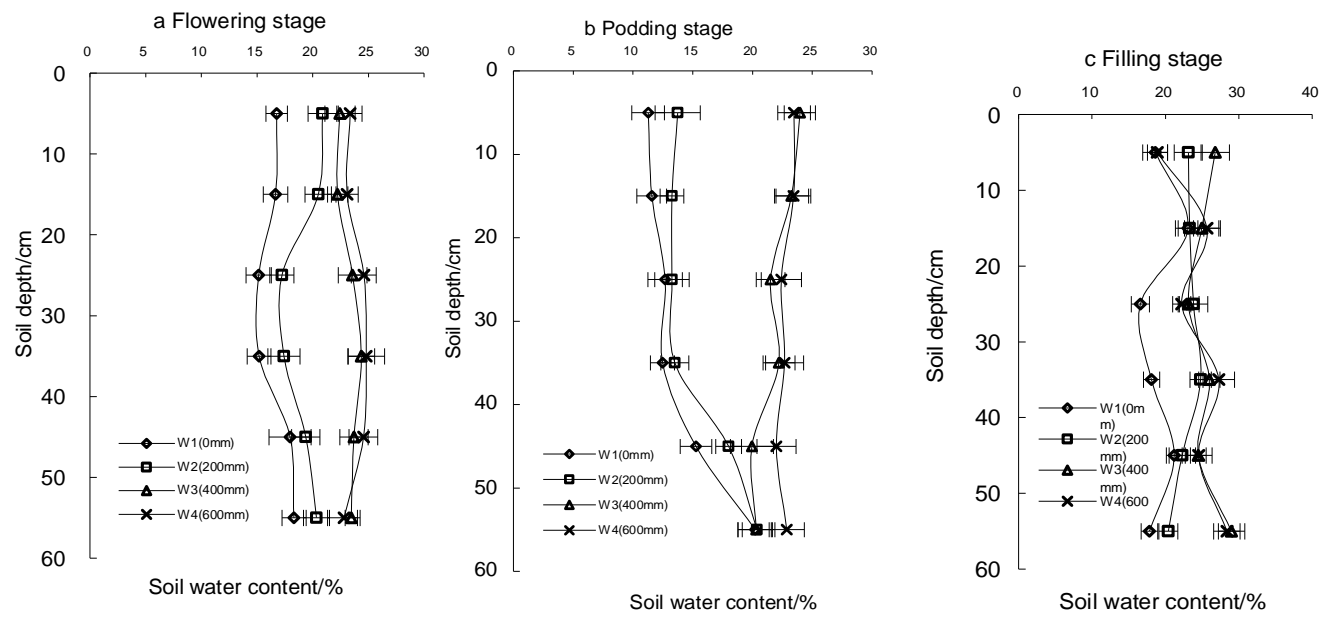

Fig. 1. The variation of soil water content at flowering, podding and filling stages of soybean under different modes of irrigation.

An indirect relationship was observed between the intensity of irrigation and soil hardness (Fig. 2). With the increase of irrigation quota, soil hardness decreased and reached a minimum value in W4. The decreasing trend of hardness at flower stage was observed as $0.02-0.76,0.29$ 1.56 and $0.74-1.89 \mathrm{MPa}$ in W2, W3 and W4, respectively (Fig. 2a). Almost similar trend of variation was also observed both at podding and graining stages of soybean (Fig. 2b, c). The changes in hardness for W3 and W4 were the same in different periods. Increased soil water 
content resulted corresponding reduction in soil hardness. The variation of soil hardness at different growth stages followed a reverse pattern with the increasing irrigation $\mathrm{W} 4<\mathrm{W} 3<\mathrm{W} 2$ $<\mathrm{W} 1$.
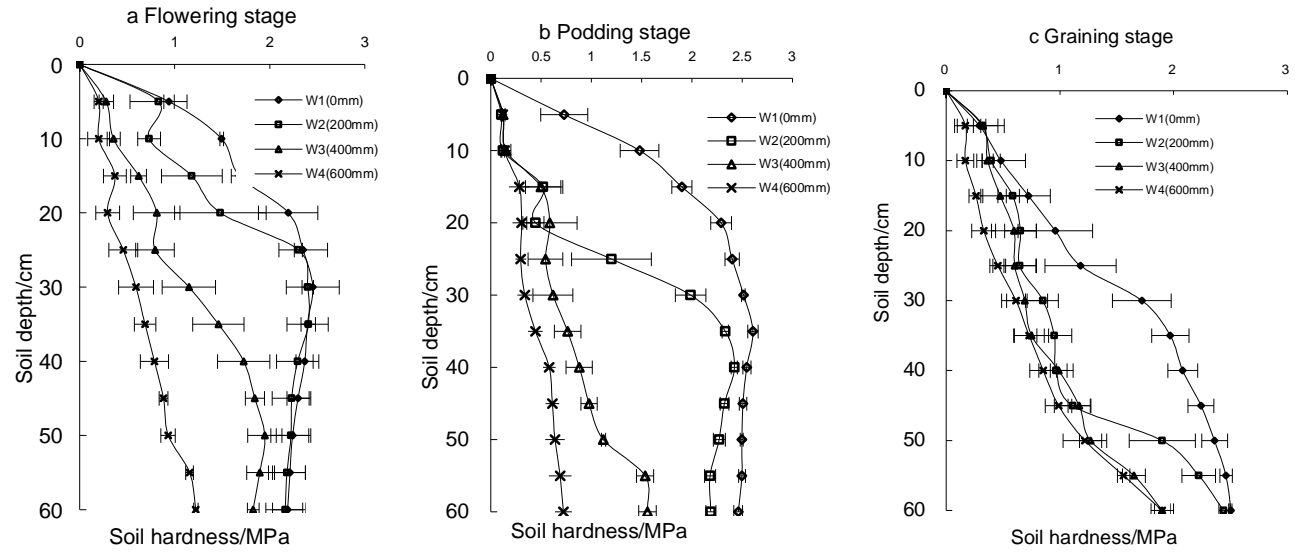

Fig. 2. Soil hardness over a vertical soil depth profile at flowering, podding and graining stages of soybean at varying mode of irrigation.
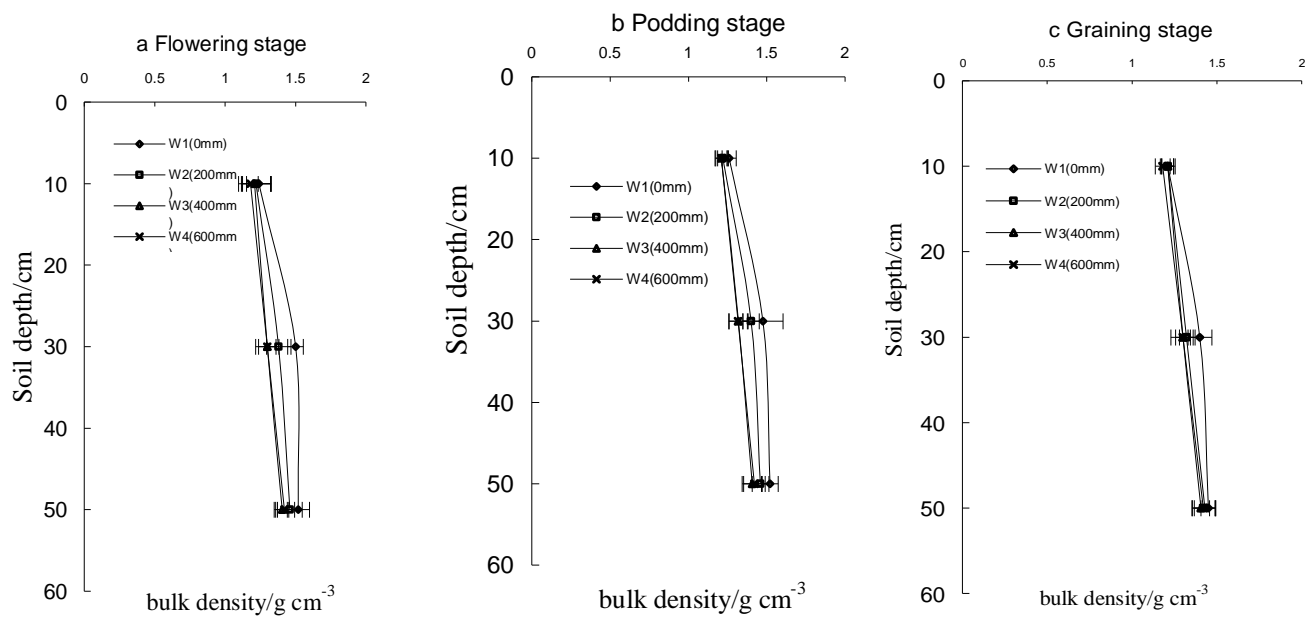

Fig. 3. Variation in the soil bulk density under different irrigation pattern and growth stages of soybean.

Soil bulk density followed slightly increasing pattern over the increasing depth profile in all the stages of soybean growth (Fig. 3). The soil bulk density in the control (W1) was the largest, with increasing amount of irrigation, it decreased, and the lowest value was observed in W4 in different periods. At flowering stage, soil bulk density of control (W1) was higher than that of W2, W3 and W4 (Fig. 3a). However, at the pod stage this parameter decreased by a range of 0.02 $0.12,0.03-0.20$ and $0.06-0.20 \mathrm{~g} / \mathrm{cm}^{3}$ in W2, W3 and W4, respectively (Fig. 3b). At seed filling period of soybean, in W2, W3 and W4 the range varied from 0.04-0.08, $0.05-0.16$ and $0.05-0.16$ $\mathrm{g} / \mathrm{cm}^{3}$, respectively (Fig. 3c). Soil moisture content increased, hardness decreased, soil permeability was improved, soil capacity was decreased, and the order of soil capacity change in different growing stages was $\mathrm{W} 4<\mathrm{W} 3<\mathrm{W} 2<\mathrm{W} 1$. 

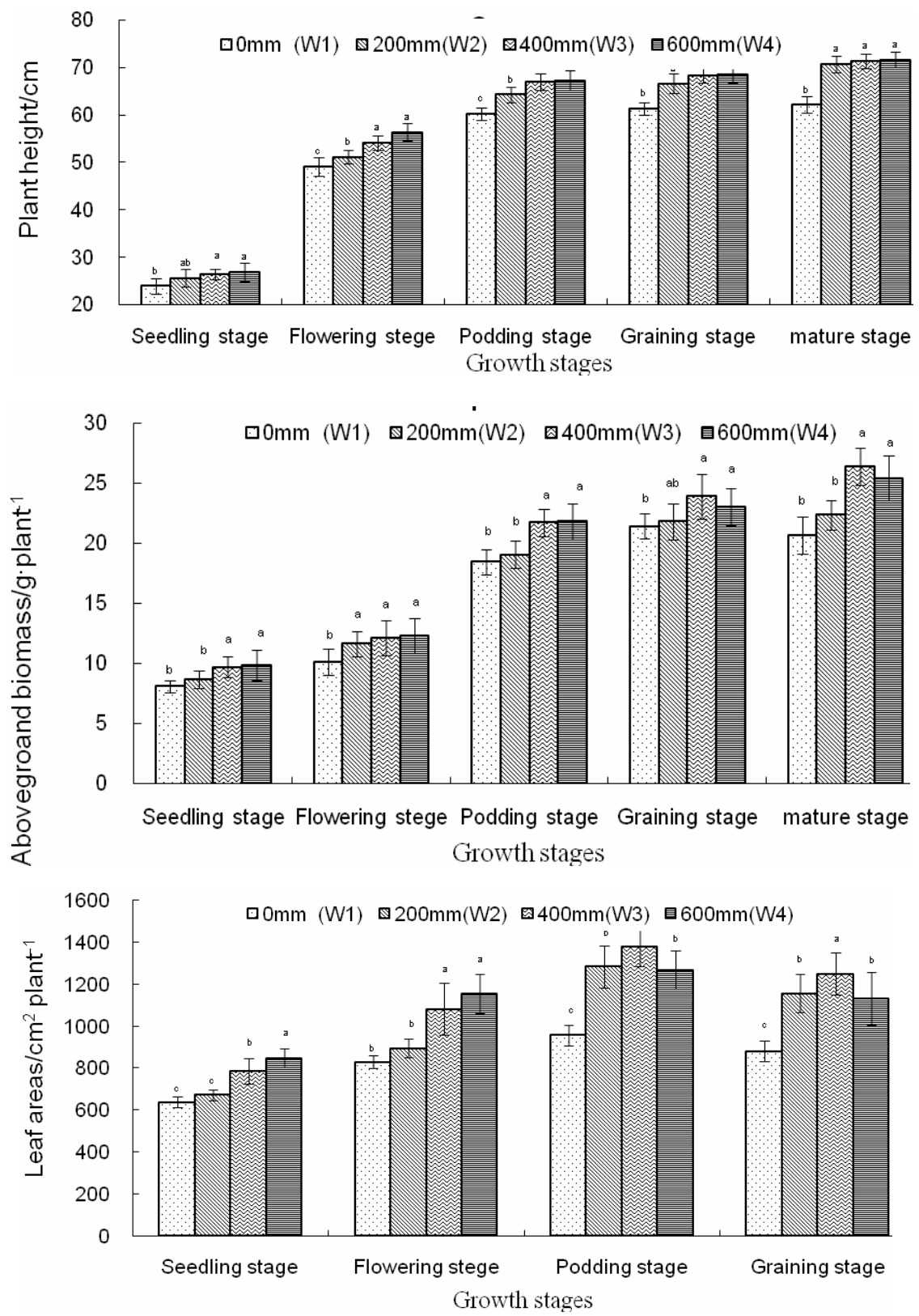

Fig. 4. The variation of plant height (a), aboveground biomass (b), leaf areas and (c) of soybean at different growth stages under different irrigation.

Data obtained on different growth indices of soybean plant at seedling, flowering, podding and graining stages at different levels of irrigation are presented in Fig. 4. Plant height showed an increasing order with the increasing irrigation at seedling and flowering stage (top panel of Fig. 4a). But at podding, graining and mature stages plant height did not change at W3 and W4. It 
means a further increase in irrigation at a rate of $400 \mathrm{~mm}$ (W3) and $600 \mathrm{~mm}$ (W4) did not bring any change in the plant height of the experimental soybean crop. This kind of response was also evident in case of above ground biomass but at seedling and flowering stages and too some extent at podding stage. At graining and mature stages, the aboveground biomass dropped with highest rate of irrigation i.e., $600 \mathrm{~mm}$ at W4 (middle panel of Fig. 4). Leaf area followed an increasing order with increasing irrigation but only at seedling and flowering stages. For podding and graining stages, the increasing trend sustained until W3 (irrigation with $400 \mathrm{~mm}$ water), but reduced when the irrigation rate increased to $600 \mathrm{~mm}$ at W4 (bottom panel of Fig. 4).

Results obtained from two years of study (2015-2016) showed that grain yield increased firstly and then decreased with the increasing amount of irrigation and the highest yield was achieved at W3 (Table1). W3, W4 and W2 yielded significantly higher than that of W1 and W3 yielded more crops than that of W4 and W2. Compared with W1, the yield of W3, W4 and W2 increased by 83.68 and $46.69 \%, 61.58$ and $39.47 \%, 23.51$ and $20.21 \%$, respectively in 2015 and 2016 . There was no significant difference in the effect of irrigation on spring soybean node number but affected in pod number and grain number. The results showed that the effect of irrigation on the yield of soybean was mainly affected by the pod number and grain number.

Table 1. The variation of yield and its components in no-tillage soybean under different irrigation.

\begin{tabular}{lllccc}
\hline \multicolumn{1}{c}{$\begin{array}{c}\text { Treatments } \\
(\mathrm{mm})\end{array}$} & Node number & Pod number & $\begin{array}{c}\text { Seed } \\
\text { number }\end{array}$ & $\begin{array}{c}\text { Yield } \\
(\mathrm{kg} / \mathrm{ha})\end{array}$ & $\begin{array}{c}\text { Increase } \\
(\%)\end{array}$ \\
\hline 2015 & & & & & \\
W1 $(0)$ & $14.50 \mathrm{aA}$ & $26.53 \mathrm{bB}$ & $59.93 \mathrm{cC}$ & $2014.72 \mathrm{cC}$ & 100.00 \\
W2 (200) & $14.70 \mathrm{aA}$ & $27.20 \mathrm{bB}$ & $61.07 \mathrm{bB}$ & $2488.28 \mathrm{bB}$ & 123.51 \\
W3 (400) & $15.60 \mathrm{aA}$ & $39.93 \mathrm{aA}$ & $79.67 \mathrm{aA}$ & $3700.69 \mathrm{aA}$ & 183.68 \\
W4 (600) & $15.40 \mathrm{aA}$ & $36.33 \mathrm{aA}$ & $74.40 \mathrm{aA}$ & $3255.33 \mathrm{bA}$ & 161.58 \\
2016 & & & & \\
W1 $(0)$ & $13.53 \mathrm{aA}$ & $25.13 \mathrm{bB}$ & $61.20 \mathrm{cC}$ & $2060.86 \mathrm{cC}$ & 100.00 \\
W2 (200) & $14.07 \mathrm{aA}$ & $27.40 \mathrm{aA}$ & $64.53 \mathrm{bB}$ & $2477.29 \mathrm{bAB}$ & 120.21 \\
W3 (400) & $14.40 \mathrm{aA}$ & $29.13 \mathrm{aA}$ & $79.67 \mathrm{aA}$ & $3029.26 \mathrm{aA}$ & 146.99 \\
W4 (600) & $14.80 \mathrm{aA}$ & $28.60 \mathrm{aA}$ & $74.20 \mathrm{aA}$ & $2874.25 \mathrm{aA}$ & 139.47 \\
\hline
\end{tabular}

Values in the same column followed by different capital and lowercase letters are different at 0.01 and 0.05 probability level, respectively; similarly, hereinafter. 'Number' indicated with the column parameter in the above-mentioned table means per plant.

Dryland farming agriculture in Sanjiang plain of Heilongjiang province mainly depends on feeding the crops by rain. Natural rainfall plays a decisive role in the crop water and rainfall distribution since the latter parameter is uneven in almost every year. The Sanjiang plain climate is continental monsoon climate and drought often occurs. All these greatly affects the growth and yield of crops in Heilongjiang Province. Cropping system in Heilongjiang Province declines the soil fertility accompanied by gradual soil erosion. It is estimated that annual drainage of surface water is $0.3-1.0 \mathrm{~cm}$ in Heilongjiang Province. Soil erosion and water loss thus weaken the functional strength of agricultural land in the area (Wei et al. 2011). The plough layer increased and thickened and the thickness of arable land in the rural area was only $15 \mathrm{~cm}$ or so, which severely restricted the land productivity. No-tillage has several advantages which can reduce 
mechanical compaction, soil hardness and erosion. It has been reported that the soil hardness under no-tillage method can be reduced by $1.1 \%$ compared with the conventional tillage method (Wang 2011).

Irrigation can improve soil physical properties. The results of this study indicated that the increase of drip irrigation directly improves the soil moisture content from $0-60 \mathrm{~cm}$ depth. Similar result was also obtained by Zhao et al. (2016) who also concluded that at flowering and podding stage of soybean crop, drip irrigation increased the water content of the soil by $9.63-12.20 \%$. Water saturation occurred when the irrigation volume reached more than $400 \mathrm{~mm}$ and the variation of soil water content was not obvious. Surface water accumulated when irrigation continued, this phenomenon actually depressed the growth of the above-ground biomass and mass growth. The soil hardness is an important index of the crop growth and yield and this factor related positively with soil depth (Yang and Li 2008, Wienhold et al. 2013). The previous research showed that soil hardness depresses the growth of soybean if the hardness goes over 1.2 $\mathrm{Pa}$, but the present research showed that within $400 \mathrm{~mm}$ irrigation and a soil hardness of $1.2 \mathrm{~Pa}$, the irrigation is beneficial in order to decrease soil hardness and bulk density.

Irrigation can promote crop growth and increase crop yield. Previous studies showed that irrigation could increase plant height, accumulate dry matter and leaf area of soybean (Mao 2009, Ge et al.2011, Li et al. 2016). Results of the present study showed that the plant height increased with the increasing amount of irrigation, but the variation of plant height was not obvious when the irrigation amount was above $400 \mathrm{~mm}$ (W3). This indicates that the effect of water on plant height is very small. The aboveground biomass and leaf area of soybean increased significantly with irrigation, which indicated that irrigation could improve the quality of soybean. But a very high amount of irrigation as tested $(600 \mathrm{~mm}$, at W4) in the present study showed a decrease in the above ground biomass at the seed filling stage of soybean. Leaf area parameter also declined in the same manner too.

Results obtained in the two-study year 2015 and 2016, highest yield of soybean was 3700.69 and $3029.26 \mathrm{~kg} / \mathrm{ha}$, respectively. The soybean growth index was the key factor affecting soybean yield, so from this study it may be concluded that the highest yield of soybean occurs under 400 $\mathrm{mm}$ irrigation (W3). A series of 4 different kinds of drip irrigation was used in the experiment and it was observed that different irrigations have different impacts on the growth and development, physical indexes, yield and yield characters of spring soybean. The soil physical properties, soil moisture content, soil hardness and bulk density were improved by different irrigation which followed W4> W3> W2> W1 order of variation. The plant height shoot biomass and leaf area increased with different irrigation amount but the upper shoot biomass and leaf area index decreased. Pod and grain number could be increased by different irrigation amount which finally affected yield and yield traits of soybean. Within the 2 years of study, compared with W1, the yield of soybean significantly increased by 83.68 and $46.99 \%, 61.58$ and $39.47 \%, 23.51$ and $20.21 \%$, respectively and the average yield followed W3> W4> W2> W1 of the irrigation pattern thus tested.

The results thus showed that different irrigation amount could improve soil physical properties, growth indexes, yield and yield characters. Based on the analysis of growth and yield traits, W3 was found to be the best treatment for high soybean productivity in the study area.

\section{Acknowledgments}

The financial support received from the Special Fund for Agro-scientific Research in the Public Interest (No.201503116-01) is gratefully acknowledged. The support actually made it 
possible to carry out the experiments at the Jiamusi Branch, Heilongjiang Academy of Agricultural Sciences, China.

\section{Reference}

CSS (The Chinese Society of Soil) 2000. Soil agricultural chemical analysis methods. Beijing: China's Agricultural Science and Technology Press. pp. 495.

Ge Y, He XL, Wang ZH and Song CJ 2011. The influence of different irrigation water on soybean growth and yield under drip irrigation. J. Shihezi Uni. (Natural Science) 29(3): 357-360.

Hamza MA and Anderson WK 2005. Soil compaction in cropping systems-A review of the nature, causes and possible solutions. Soil Till. Res. 82(2): 121-145.

Li DY and Zhang SW 2010. Evaluation on coordination degree between water resources and social economic development in Heilongiiang Province. J. Arid Land Res. Env. 24(1): 8-11.

Li SZ, Zhang JX, Li CY, Chu GH and Tang CQ 2016. Characteristics of dry matter accumulatioN distribution and yield of high-yield soybean. J. Chin. Agri. Uni. 21(7): 21-28.

Liu S, He WQ, Yan CR and Liu Q 2010. Effects of different tillage managements on soil physical properties in dry land. Agri. Res. Arid Areas. 28(2): 65-70.

Mao HX 2009. Effect of different drip irrigation treatments on dry matter accumulation and physiological parameters in soybean. Soybean Sci. 28(2): 247-250.

Nippert JB, Wieme RA, Ocheltree TW and Craine JM 2012. Root charac-teristics of C4 grasses limit reliance on deep soil water in tall grass prairie. Plant Soil. 355(1-2): 385-394

Qiang XM, Sun JS, Liu H, Ning HF and Wu XL 2016. Effects of drip irrigation quota on yield and water productivity in watermelon-cotton intercropping system. Trans. Chin. Soc. Agri. Eng. 32(19): 113-119.

Ren HY, Cui ZC, Shen NC, Bai YM and Cai DX 2015. Study on relationship between accumulation of dry matter and water at growth stages of soybean. Chin. J. Oil Crop Sci. 27(3): 41-44.

Wang ZH, Zheng XR and Jiang GJ 2015. Effects of irrigation amount on the growth and physiological indexes of drip irrigated spring wheat. J. Nucl. Agri. Sci. 29(3): 0538-0548.

Wang CJ 2011. Effect of conservation tillage measures on crop yield and soil fertility. Yang Ling: Northwest Agri. Forestry Uni. Master's Thesis.

Wei S, Wang JG and Gu WR 2011. China granary-grain production analysis and resolving strategies in Heilongjiang Province. J. Northeast Agri. Uni. 42(7): 1-7.

Wienhold BJ, Varvel GE, Johnson JMF and Wilhelm MM 2013. Carbon source quality and placement effects on soil organic carbon status. Bioenergy Res. 6(2): 786-796.

Wu JC, Yang YH, Jia YY, Wang HB and Guan XJ 2011. Effect of different compensation irrigation on yield and water-use-efficiency of winter wheat in henan province. J. Henan Agri. Sci. 40(1):74-78.

Xing YY, Zhang FC, Wu LF, Fan JL, Zhang Y and Li J 2015. Determination of optimal amount of irrigation and fertilizer under drip fertigated system based on tomato yield, quality, water and fertilizer use efficiency. Trans. Chin. Soc. Agri. Eng. 31(Supp.1): 110-121.

Yang XJ and Li CJ 2008. Impacts of mechanical compaction on soil properties, growth of crops, soil-borne organisms and environment. Sci. Agr. Sin. 41(7): 2008-2015.

Zai YP and Tang XP 2008. A study on the problem of protective cultivation in the north of China. J. Xi'an Shiyou Uni. (Social Sciences) 17(3): 36-39.

Zhang DH, Lou S and Liu HP 2014. Analysis on the status and potential problems of grain production in Heilongiiang Province. Res. Agri. Mod. 35(5): 525-530.

Zhang GQ, Wang KR, Xiao CH, Xie RZ, Hou P, Li J, Xu WJ, Chu ZD, Liu GZ, Liu CW and Li SK 2015. Effect of drip irrigation on yield and water use efficiency of spring maize with high yield in Xinjiang. J. Maize Sci. 23(4): 117-123.

Zhao LJ, Xue LH, Sun QK and Zhang JX 2016. Effect of different irrigation and nitrogen application on water consumption characteristics and the water and nitrogen use efficiencies under drip irrigation in winter wheat. J. Trit. Crops 36(8): 1050-1059. 
Zhang YQ, Zhang N, Li YJ, Peng JL, Su LL and Xu WX 2016. Effect of drip irrigation amount on water consumption characteristics and dry matter accumulation and transformation of summer soybean in north xinjiang. Res. Soil Water Conser. 23(2): 111-115.

Zhao EL, Ge HL, Gong ZP, Ma CM, Wang XJ and Zhang SW 2014. Effect of levels of irrigation on plant height and yield in spring soybean. Crops 31(1): 125-128.

(Manuscript received on 16 May, 2018; revised on 16 July, 2018) 